\title{
Multimodal Analysis on Product Placement in Korean Drama: "Goblin"
}

\author{
Natalia Kristiva Utomo, Setefanus Suprajitno \\ English Department, Faculty of Letters, Petra Christian University, Siwalankerto 121-131, Surabaya \\ 60236, Indonesia. \\ E-mail: nataliakristivautomo@gmail.com, steph@petra.ac.id
}

\begin{abstract}
Many companies try to find innovative ways of reaching their target market and promoting their products. Product placement (PPL) is one of such innovative ways. PPL has become popular in marketing communication because the promotion in it is quite subtle. It happens because in PPL, the advertisement is integrated in the structure of the narratives of TV series or films where PPL takes place. Thus, PPL can skirt the negative view toward advertising. In this study, we examine how PPL convey advertising messages in Korean drama, Guardian: Great and Lonely God (Goblin). In so doing, by using multimodal theory we analyze the verbal and non-verbal communication practices found some scenes of the Korean drama, and the meaning of PPL semiotic resources in those scenes express. Our findings show that PPL conveys the advertising messages through the acting, the facial expression, and the shot of products.
\end{abstract}

Keywords: Product Placement, Multimodal, Modes, Goblin, Verbal and Non-Verbal Communication

\section{INTRODUCTION}

Nowadays, due to the increasing competitiveness in the global market, companies have to innovate in order to trigger consumers' desire to buy their product. They also need to shape its own uniqueness to catch consumers' attention. Because of the development of digital media and the fact that customers are more well-informed, "businesses have deemed it necessary to establish more integrated and consistent marketing communication based on the characteristics of media as advertising strategies" (Chae \& Sun, 2013, p. 55). Thus, they also have to find interesting ways to advertise their products. Currently, product placement (PPL) is the most popular method among companies to promote their product instead of placing advertisement on $\mathrm{TV}$, newspapers, and magazines. One characteristic of PPL is "that consumers who are exposed to this advertising technique are not able to avoid this advertising content while for instance ondemand audiovisual media services enable viewers to avoid television commercials" (Spielvogel, Naderer \& Matthes, 2020, p. 2).

Product placement is sometimes viewed as a guerilla tactic to fight consumers' increasing resistance to advertising exposure and may be less likely to irritate consumers for two reasons. First, because product placements occur within the programming, they do not require commercial interruption. Second, product placements focus on passive persuasion rather than overt, hard-sell tactics. (Gangadharbatla and Daugherty, 2013, p. 25)

Thus, the popularity of PPL is due to its ability to "hide" the advertising messages. PPL can skirt the negative view toward advertising.

PPL is defined as "an advertising technique in which branded products or brand identifiers are deliberately embedded within entertaining content such as movies or television shows" (Spielvogel, Naderer \& Matthes, 2020, p. 1). In this technique, advertisements are 
integrated in the structure of the narratives of TV series or films where PPL takes place. Advertising messages are "hidden" or subtle. Thus, the advertisements influence the audience unobtrusively. As a result, without realizing it, the audience may link the world of the TV series or films with their social worlds, including their consumptive behaviors, and "these linkages could be important since the decision to purchase a product is likely to be the result of such linkages" (Gould, Gupta, and Grabner-Krauter, 2000, p. 43). Under the influence of the world of TV series or films, the audience may also ascribe certain meanings to the products advertised in the PPL.

PPL seems to be a new method of advertisement. However, it has been used over last decades by a number of companies to advertise their products. Newell, Salmon, and Chang (2006) write that in E.T. the Extra-Terrestrial (1982), a film directed by Steven Spielberg, audience can see the PPL of a chocolate company, Hershey, in which the trails of its Reese's pieces of chocolate show the alien its new home. Lehu and Bressoud (2007) note that luxurious car manufacturers also jump into the wagon by paying movie producers in order that their products are featured in the movies, for example Aston Martin cars in the James Bond films since Die Another Day (2002), and BMW Mini Cooper in The Italian Job (2003). Since then on, the way marketers put their product in PPL in TV series or films is getting more and more creat9ve and innovative (Newell, Salmon, and Chang, 2006).

At first, companies chose films as the venue for their PPL. However, nowadays they targets TV series promoting their products. This phenomenon is triggered by the popularity of Korean TV dramas in various countries in Asia. The popularity of Korean dramas across Asia inspires many companies to advertise their products in popular Korean dramas through PPL. The use of PPL is proven to be successful. As noted by Chan \& Jie, the widespread of Korean TV dramas provides an increase in the export sector especially in the cosmetics sector (2017, p. 1389). For instance, South China Morning Post (SCMP) reported that the sales of the skincare and lipstick from brand Amorepacific which were used by the actor and actress in My Love from the Star (2013) increase up to $400 \%$ in China ("South Korean TV dramas exploit success," 2014). The increasing sales as reported by SCMP occurs because the products advertised in PPL gained much attention from the viewers. The reason why PPL in Korean TV dramas is quite successful is that the broadcasting in Korean dramas shows really strong content display, which thus definitely leads into a consumption (Chan \& Jie, 2017, p. 1392)

The use of PPL in Korean TV dramas is actually quite simple. Inside the story, the actors and actresses use certain products and then add some verbal cues to raise the value of the products. For example, in Descendant of the Sun (2014), the main actress Song Hye Kyo demonstrates brand lipstick Laneige. Descendant of the Sun is a Korean TV drama that received great response from audiences across the world. As a result, it was considered as the most popular and highest rated in 2016 (gdhunter, 2017). In Descendant of the Sun, Song Hye Kyo, the brand ambassador of Laneige lipstick, is pictured together with the lipstick itself. Since that scene was aired, Laneige no longer mentions the lipsticks' brand name. Instead, it uses "Song Hye Kyo lipstick Descendant of the Sun" (Figure 1). The PPL of Laneige in Descendant of the Sun was so successful that, according to The Strait Times, "the 16-episode series, which ends its run in South Korea this month, will generate more than three trillion won ( $\$$ \$3.5 billion) worth of economic effects in terms of exports, domestic spending and tourism" ("Hit K-drama boosts sales." 2016). 


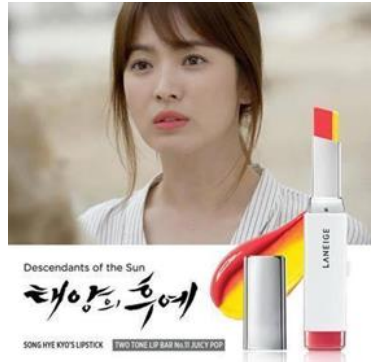

Figure 1: The Brand of Laneige and Song Hye Kyo from Descendant of the Sun

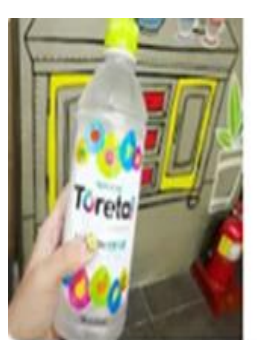

Toreta Mineral Water Korea Minuman Air Drama Goblin Kpop Vitamin Fruit

IDR 40,000

Tokopedia

Drink at Tokopedia

In this study, we are analyzing the PPL in a Korean drama, Guardian: The Lonely and Great God (2016), also known as Goblin or Dokkaebi in Korean. In Korean mythology, Dokkaebi is a goblin-like monster who seldom harassed good-hearted people (Bane, 201, p. 104). A writer, Kim Eun Sook, uses this monster as her inspiration to write an interesting script for TV series, and chooses the name of the monster, Dokkabei, translated into Goblin, as the title of this TV drama. When it was released, Goblin was one of the most watched Korean drama through Video of Demands (VOD) and beats the number of viewers of Descendant of the Sun and Reply 1998, two other most popular Korean drama. CNN Indonesia reports that Goblin generates profits up to 14 million won or 165 million rupiah (Armenia, 2017). Furthermore, entertainment news portal Okezone reports Goblin has achieved many awards such as Best Drama Award 2017, Star of The Year, Popular Character Award and Best New Actor Award (Hidayati, 2017).

What makes Goblin interesting is that although it was highly criticized (Doo, 2017), the PPL in the drama is proven to be successful. This is supported by the fact that many items of the merchandise of Goblin is sold online. For example, the Toreta hydration drink from the drama is being sold with words like "Dijual minuman Goblin" (Figure 2). This is one evidence that actually the product placement was successful. The controversy surrounding it triggers our interest in analyzing the PPL in this drama.

Besides Toreta Hydration Drink, there are other products that are placed in Goblin. Those are Galaxy S7s Samsung mobile phone, Baskin and Robbins, Kanu Coffee, SUBWAY, Pure Love White Musk Perfume, Dal.Komm Coffee, and Haru Yache Organic Daily Vegetables Yoghurt. In these study, we analyze two of them that dominate the PPL and emerge frequently in the drama. They are Toreta Hydration Drink and Dal.Komm Coffee.

PPL in dramas and films usually highlights the products promoted, and their logo, brand name, and packaging. Because of this, in our analysis we use theory of multimodality which inspire us to investigate the six modes of communication, namely, linguistic, audio, spatial, oral, visual, and gestural modes (Anstey \& Bull 2010; Chan \& Chia 2014). However, in analyzing the PPL in Goblin, we focus on three modes only. Those three modes are the oral, visual, and gestural modes. We choose these three modes because they are mostly used and available in the drama; the oral mode is in the scripted conversation, the visual mode in the shot of its brand or product, and the gestural mode in the actors' and actresses' facial expression. Through our analysis, we investigate how the messages of the PPL of Toreta Hydration Drink and Dal.Komm Coffee in this drama series are conveyed through verbal and non-verbal expressions; and what the semiotic resources in the drama series express. 


\section{METHOD}

In this study, we use a qualitative content analysis method to analyze the data. This method, in which a research technique is employed for making replicable and valid inferences from texts (or other meaningful matter) to the context of their use (Krippendorff, 2004, p.18), is chosen because it is very suitable for examining verbal and non-verbal expressions convey the messages in the PPL in drama series as the technique in this method provides new insights, increases a researcher's understanding of particular phenomena, and informs practical actions. It is also suitable for analyzing the meanings of an advertisement through the systematic practice of describing the meaning of qualitative material (Schreier, 2012, p.1).

Data for this study were taken from the PPL in the sixteen episode of Goblin, supported by the ones taken from the official website from companies that use PPL for promoting their products in this drama. The data are in the forms of the images the products or services promoted in the PPL, gesture and facial expressions, and the English subtitle of the conversations of actors and actresses in the drama, the visual (the images of the product or service) and last of all was the gesture (gesture and facial expression).

\section{FINDINGS AND DISCUSSION}

The research questions of this study concern how the messages of the PPL of Toreta Hydration Drink and Dal.Komm Coffee are conveyed through verbal and non-verbal expressions and what the semiotic resources in this drama express. Our findings yields the way Toreta Hydration Drink and Dal.Komm Coffee use PPL as their way of promoting their products in Goblin, and the meanings the semiotic resources in this drama expresses.

\section{Toreta Hydration Drink}

Toreta Hydration drink is a product from Aquarius Sports Drinks. It is a hydration drink made of water mixed with the juice from ten fruits and vegetables. It was first released in 2006. Since then, it has become famous because it appears in popular Korean dramas and variety shows. In its official website (http://www.lghnh.com/global/brand/detail.jsp?gbn=3\&bid1=R036), the producer of Toreta writes that people can drink every day because the drink can help them relieve their fatigue after a long day of work.

In one scene (Figure 3), Toreta is shot in such a way that the bottle on the table is in an open state and people can see the brand. The actress is sitting facing the camera and doing nothing. This scene signifies that the drink has been consumed. Next to the drink there is a small bowl containing snacks. It shows that this drink is suitable for accompanying your snack time. The message sent by this scene is that Toreta can be consumed anytime.

Meanwhile, the scene in Figure 4, the visual mode highlights the position of Toreta, located in the cooler behind the actresses and above the most famous international brand, Coca Cola. As reported from Interbrand 2019, Coca Cola is ranked 5th as the best global brand (https://www.interbrand.com/best-brands/best-global-brands/2019/ranking/cocacola/). In this scene, Toreta is placed in the position whereby it is easily visible. In this way, the position of Toreta is at the eye level. Within this position, according to Kendall (2014), "one phrase commonly used is "eye level is buy level, indicating that products positioned at eye level are likely to sell better." Thus, this position implies that this drink is more sought after, higher sales, and not inferior to the famous brand Coca Cola. 


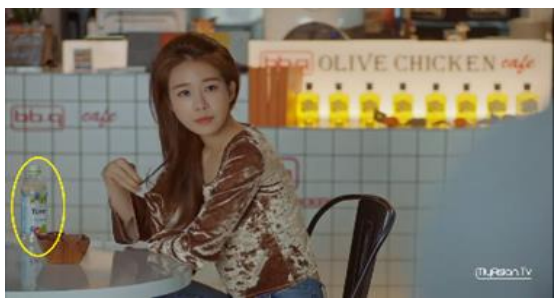

Figure 3

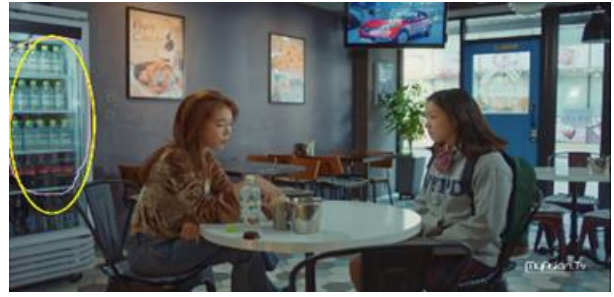

Figure 4

The oral, visual, and gestural modes of the scene in Figure 5 seem to emphasize the values of Toreta. The visual mode shows that the actress is holding a bottle of Toreta near her face and shows the Toreta brand in the Korean alphabet. The opened bottle implies that the actress has drunk it. This is strengthened by what she is saying, "Can you see how hard I'm trying? I drink this every day for my skin." This signifies that Toreta Hydration drink is good for women's skin complexion. Having a good complexion means being beautiful. The visual and oral modes create an impression that Toreta has benefits, especially for women's skin, as the actress demonstrates in this scene. The gestural mode (facial expression) increases the attractiveness of Toreta, which is suitable for women's healthy skin. The actress shows innocent yet beautiful expression while holding the bottle near her face. Thus, in this scene, Toreta Hydration drink wants to say to the audiences that it has many benefits for women, as reflected in its slogan "Good water from 10 fruits and vegetables, low-calorie rehydration, Toreta." Thus, this scene fits with the slogan.

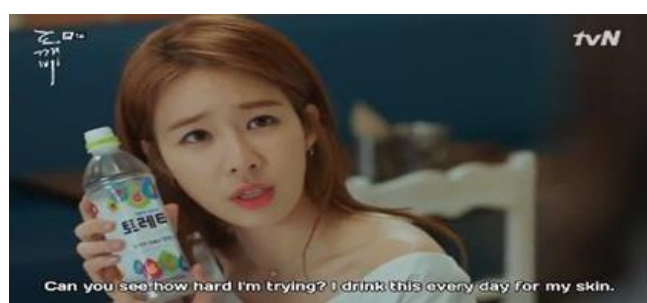

Figure 5

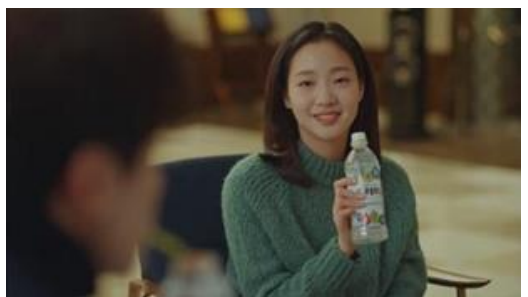

Figure 6

The image of Toreta as a thirst quencher is portrayed through the oral, visual, and gestural mode in Figure 6 . The actress says that she is thirsty while holding the product. It implies that people can grab Toreta to quench their thirst. Toreta's image as a thirst quencher is also strengthened by the actress' facial expression, which shows a happy, wide smiling, and bright face. It indicates that Toreta is a good thirst quencher. It is so fresh that people who drink it want to drink it more. Other than being fresh, Toreta also wants to convince the viewers that whoever drink its product will feel happier and more satisfied as depicted by the actress' wide smile. The message of thirst quencher is also reflected in Toreta's slogan, "When you're thirsty or in need refreshment, enjoy this light drink whenever and wherever," and this scene fits with its slogan. In this case, Toreta is depicted as a great and fresh thirst quencher.

In conclusion, our analysis on the PPL of Toreta shows that there are four messages that Toreta wants to say to the viewers of Goblin. The first message is that Toreta is a beverage that people can drink anytime. This message is very clearly stated in the scene where the Toreta is placed next to a bowl of snack. The next message is that Toreta is a salable and popular, as reflected in the scenes where Toreta is located at the top of the shelf above other drinks. This position indicates that Toreta is most likely sought after by people. The third message is that Toreta is beneficial for skin, shown through the oral, visual, and gestural mode in which the actress is holding the product near to her face while saying "Can you see how hard I' $m$ trying, I drink this every day for my skin". This scene creates an impression that Toreta has benefits for 
women's skin. The fourth message is that Toreta is great for a thirst quencher. One of the scenes that illustrates it is that drinking Toreta, the actress shows a happy and smiling face. It means that Toreta Hydration is truly working as a thirst quencher.

\section{Dal.Komm Coffee}

Dal.Komm Coffee is a South Korean cafe. Originally, it was a producer and processor of coffee beans. However, in 2011 it started to run cafe in South Korea. Since its appearances in a number of drama series, Dal.Komm Coffee has gained popularity both in South Korea and overseas. Therefore, Dal.Komm Coffee already has franchises in Singapore and Malaysia. This cafe mainly serves beverages, such as coffee, milkshake, and juice. As mentioned in its official website (http://www.dalkomm.com/english/Dal.komm), Dal.Komm Coffee provides its customers free $\mathrm{Wi}-\mathrm{Fi}$ access, charging points, free ice water, and music because it wants to serve the best to the costumes, in line with its tagline, "provide a sense of closeness and special value to customers."

In one scene (Figure 7), the image of Dal.Komm Coffee as a cafe that serves more than just coffee is strengthened by what the actor is saying "Which one do you want? You can get an expensive one." The "expensive" creates an impression that Dal.Komm coffee is a cafe that offers not only beverages but also lifestyle. Apart from the verbal communication, that impression is also created through what the actor wears. In this scene the actor is depicted as wearing semi-formal clothes while having his order. The fact that the actor puts on this kind of attire gives a feeling to Dal.Komm Coffee as classy and elegant cafe. It means that Dal.Komm Coffee is a cafe that provides high quality for both products and lifestyle. Through its slogan, "more than coffee", Dal.Komm Coffee purposely encourages the viewers that it offers high quality in both products and lifestyle.

Besides that, Dal.Komm Coffee also tries to inform the audience that it has many delicious products to be chosen through the non-verbal communication. As seen in Figure 8, when asked by the male character, without hesitation, the female character points her finger to grape fruit juice listed in the menu. Through this gesture, Dal.Komm Coffee wants the audience to know its other available beverages, as not all people like coffee. The Huffington Post Canada reports that men are more likey coffee drinkers than women (D'Souza, 2015). Thus, through this scene, Dal.Komm Coffee wants to attract people across the board as their customers by serving coffee and other beverages such as freshly squeezed juice, and other honey special drinks.

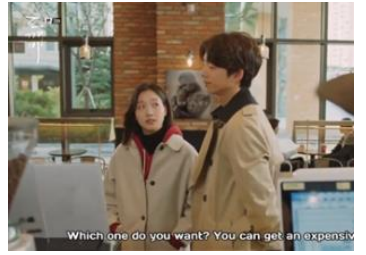

Figure 7

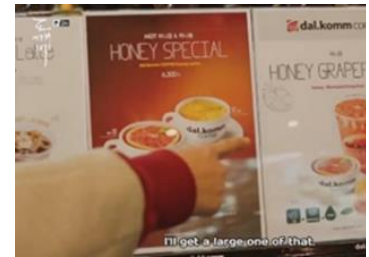

Figure 8

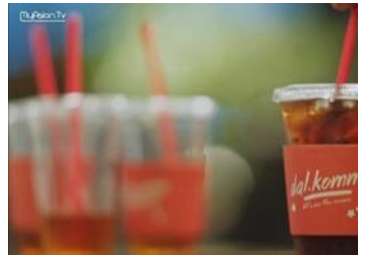

Figure 9

Since its signature beverage is coffee, Dal.komm Coffee also exposes its coffee in its PPL in Goblin. Figure 9 illustrates this exposure. This figure only shows a cup of iced Americano. The camera focuses on the cup holder printed with the words "dal.komm," and there seems to be someone who is drinking it. The visual mode in this scene creates an impression that Dal.komm iced Americano is so good and fresh that people want to drink it. Although this scene does not have any words or facial expressions, Dal.komm Coffee tries to convince the audience that its specialty in making great coffee. This is also supported by its statement in its website, that is, "We provide the world's first-rate of coffee beans and barista 
expertise to create perfect beans." This implies that Dal.Komm Coffee wants to tell the viewers that its coffee is the best choice and taste for its customers.

In Goblin, Dal.Komm Coffee also wants to show that its other tagline, "more than just a coffee," is true, as seen in Figure 10. The scene in this figure exposes the customers and the ambience of Dal.Komm Coffee. It focuses on a male customer. It implies that people can enjoy Dal.komm Coffee no matter whether they are singles or not. The fact that a customer who is alone seems to enjoy his coffee while playing with his smartphone and showing a cheerful expression indicates that Dal.komm Coffee is a very comfortable place to relax. People can spend their free time there while enjoying coffee. It means that besides offering coffee or other beverages, Dal.Komm Coffee also gives a nice place for its customers to enjoy their free time. This message is also strengthened by Dal.komm Coffee's other slogan which is "We uniquely give personal space for customers and specially created at every Dal.komm Store". (Dal.Komm Coffee, 2019). The message that Dal.Komm Coffee wants to express through this scene is that that it offers a cozy place for its customers.

Meanwhile, in the scene shown in figure 11, Dal.Komm Coffee tries to tell the audience that the atmosphere in its cafe is suitable for any customers. This scene depicts a number of customers sits there. This scene sends a message that Dal.komm Coffee is a place that various people can enjoy. Audience and infer this message from a lone girl who seems to be studying while drinking the coffee. The fact that Dal. Komm Coffee provides free Wi-Fi access and charging points shows that anyone can choose Dal.komm Coffee as a place to work, study, or relax. This message is also conveyed by Figure 12, in which a couple have been drinking some cups of coffee and sitting there for hours. This scene signifies that the cafe has good food and beverages and cozy atmosphere.

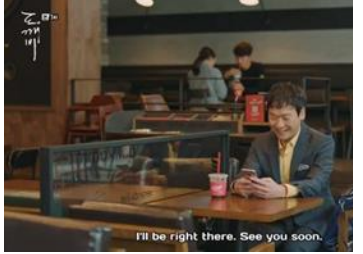

Figure 10

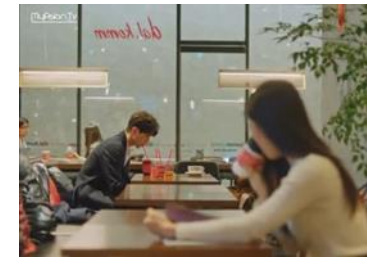

Figure 11

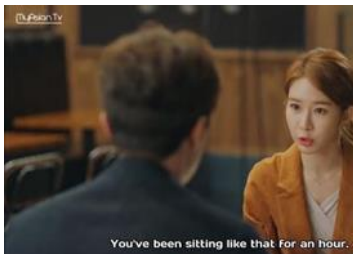

Figure 12

To sum up, our analysis on the PPL of Dal.komm Coffee finds that there are three messages that Dal.Komm Coffee points out in Goblin. The first message is how classy and elegant the cafe of Dalkomm.coffee is. As seen in Figure 7, what the actor wears, that is, semiformal clothes and says, namely, "You can choose the expensive one," signifies that Dal.Komm Coffee offers not only products but also lifestyle. The second message is how good the quality of its products is. Figures 8 and 9 highlight the products in such a way that they look good, fresh, and appetizing. The third message is how cozy and comfortable the atmosphere of its cafe is. It is precisely depicted in Figures 10, 11, and 12, where all scenes focus on its interior design and various customers. Even though most of the scenes do not have any verbal communication, it is still delivered the message clearly.

\section{CONCLUSION}

In this study, we find that product placement (PPL) in Goblin consists of both verbal and non-verbal communication. In this case, the verbal communication is the scripted conversation between the male character and female character, meanwhile the non-verbal communication is from the visual and facial expression. However, PPL does not rule out the possibility where it is only non-verbal communication which delivers the message. I also find 
that through creativity and innovative strategy using PPL as the way of promotion, it gives meaningful messages to the audience, which we analyze through three modes, namely, oral, visual, and gestural mode. The three modes are able to reveal the hidden message that companies want to deliver in the product placement.

There are many products promoted in Goblin, but we only choose two of them. Those are Toreta Hydration drink and Dal.Komm Coffee. We choose them because they frequently appear in various scenes in this drama. The PPL contains many semiotic resources that delivering the messages the products want to express. The PPL starts in line with the narrative of Goblin, and this makes the quality of the PPL more interesting. The audience are able to enjoy the storyline without being interrupted by advertisements because the advertisements becomes parts of the story. As a result, the viewers are unconsciously influenced by hidden and subtle advertisements

From the analysis, the PPL of the products that we analyze delivers their promotional messages through three modes, namely, oral, visual, and gestural mode. The products that we analyze are Toreta Hydration Drink and Dal.Komm Coffee. The messages that Toreta sends are: (1) it is a beverage that people can drink anytime; (2) it is a salable and popular product; (3) it is beneficial for skin; and (4) it is great for a thirst quencher. One of the scenes tha illustrates it is that drinking Toreta, the actress shows a happy and smiling face. It means that Toreta Hydration is truly working as a thirst quencher. The messages that Dal.Komm Coffee sends are: (1) it offers a classy and elegant cafe; (2) it offers good-quality products; and (3) it offers cozy and comfortable atmosphere in its cafe. These messages are created and successfully delivered through the actors' and actresses' acting and facial expression, as well as through the shots of the products promoted.

In conclusion, product placement is indeed formed and delivered through its verbal and non-verbal communication. Verbal communication is mostly used for clarifying or stressing the idea behind its products. The non-verbal communication is mostly used to reinforce the message and value of the products that have been mentioned through verbal communication. Based on the form of product placement in Goblin, we find that this product placement is both creative and very influential. The product placement indeed promote those products, just like advertisement, but one thing that makes PPL is different is that the promotion is done in a "hidden" and subtle way so that the audience may not be aware of the promotion. This makes product placement more valueable than an advertisement.

\section{REFERENCES}

Anstey, M., \& Bull, G. (2010). Helping teachers to explore multimodal texts. Curriculum and Leadership Journal: An Electronic Journal for Leaders in Education, 8(16). Retrieved from:

http://www.curriculum.edu.au/leader/helping_teachers_to_explore_multimodal_texts,315 22.html?\%20issue\%20ID=12141.

Armenia, R. (2017, April 27). Goblin kalahkan jumlah permintaan descendant of the sun. CNN Indonesia. Retrieved from: www.cnnindonesia.com/hiburan/20170427090942-220210473/goblin-kalahkan-jumlah-permintaan-descendants-of-the-sun.

Bane, T. (2016). Encyclopedia of beasts and monsters in myth, legend and folklore. Jeffroson, NC: McFarland.

Chan, A. \& Chia, C. (2017). Re-defining 'reading' in the 21st century: accessing multimodal texts. Beyond Word, 5(2), 98-105.

Chae, M. J., \& Sun, H. J. (2013). TV product placement in Korea. Journal of Promotion Management, 19(1), 54-75. doi: 10.1080/10496491.2012.736461 
Utomo: Multimodal Analysis on Product Placement in Korean Drama: "Goblin"

Chan, G., H. \& Jie, W. (2017). Do Hallyu (Korean wave) exports promote Korea's consumer goods exports? Emerging Markets Finance and Trade, 53(6), 1388-1404. doi: 10.1080/1540496X. 2017. 1313161.

Doo, R. (2017, January 6). Korean drama 'Goblin' popular but controversial. The Jakarta Post. Retrieved from: https://www.thejakartapost.com/life/2017/01/06/korean-drama-goblinpopular-but-controversial.html.

Gangadharbatla, H. \& Daugherty, T. (2013). Advertising versus product placements: How consumers assess the value of each. Journal of Current Issues and Research in Advertising, 34(1), 21-38. doi: 10.1080/10641734.2013.754706.

Gdhunter. (2017, March 23). On this day last year, "descendant of the sun" hits 30\% viewer ratings. Kdramapal. Retrived from: https://www.kdramapal.com/on-this-day-last-yeardescendants-of-the-sun-hits-30-viewer-ratings/.

Gould, S. J., Gupta, P. B. and Grabner-Krauter, S. (2000). Product placements in movies: A crosscultural analysis of Austrian, French and American consumers' attitudes toward this emerging international promotional medium. Journal of Advertising, 29(4), 41-58. doi: 10.1080/00913367.2000.10673623.

Hidayati, L. (2017, Oktober 3). Goblin menang besar di korea drama awards 2017. Okezone. Retrieved from https://celebrity.okezone.com/read/2017/10/03/598/1787681/goblinmenang-besar-di-korea-drama-awards-2017.

Hit K-drama boosts sales of South Korean products. (2016, April 2). The Straits Times. Retrieved from: $\quad$ www.straitstimes.com/lifestyle/entertainment/hit-k-drama-boosts-sales-of-southkorean-products.

Kendall, G. (2014, March 4). The science that makes us spend more in supermarkets, and feel good while we do it. The Conversation. Retrived from: https://theconversation.com/thescience-that-makes-us-spend-more-in-supermarkets-and-feel-good-while-we-do-it-23857.

Krippendorff, K. (2004). Content analysis: An introduction to its methodology. 2ed. Thousand Oaks, CA: Sage Publication.

Lehu, J. M. \& Bressoud, E. (2007, June 5-8). Viewers and brand placement in movies: New insights about viewers contribute to a better understanding of the effectiveness of the technique. The La Londe Conference in Marketing Communications and Consumer Behavior: International Research Seminar in Marketing. La Londe, France. Retrieved from: https://halshs.archives-ouvertes.fr/halshs00305723/file/Lehu_Bressoud_2007_Brand_PLacement_viewers_La_Londe

Newell, J., Salmon, C. T., \& Chang, S. (2006). The hidden history of product placement. Journal of Broadcasting \& Electronic Media, 50(4), 575-594. doi: 10.1207/s15506878jobem5004_1.

Schreier, M. (2012). Qualitative content analysis in practice. Thousand Oaks: Sage Publications. Spielvogel, I., Naderer, B., \& Matthes, J. (2020). Disclosing product placement in audiovisual media services: A practical and scientific perspective on the implementation of disclosures across the European Union. International Journal of Advertising, 1-21. doi: $10.1080 / 02650487.2020 .1781478$.

South Korean TV dramas exploit success to push products across Asia (2014, June 23). South China Morning Post. Retrieved from: https://www.scmp.com/business/companies/article/1538513/south-korean-tv-dramasexploit-success-push-products-across-asia.

D’Souza, J. (2015, May 20). Coffee consumption differs between genders, according to this infographic. Huffington Post Canda. Retrieved from: https://www.huffingtonpost.ca/2015/05/20/coffee-consumption_n_7315642.html. 